\title{
Physicians Are Often Incorrect About the Telemetry Status of Their Patients
}

\author{
Sajan Patel, MD ${ }^{1 *}$, Sayumi De Silva, $\mathrm{MD}^{2}$, Erin Dowling, $\mathrm{MD}^{3}$
}

${ }^{1}$ Division of Hospital Medicine, University of California, San Francisco Medical Center, San Francisco, California; ${ }^{2}$ Internal Medicine and Pediatrics, Chinle Comprehensive Health Care Center, Chinle, Arizona; ${ }^{3}$ Department of Internal Medicine, University of California, Los Angeles Medical Center, Los Angeles, California.

Cardiac telemetry is overused in hospitals and continues to be a source of healthcare waste. ${ }^{1-4}$ Its overuse is considered a leading issue in quality initiatives, as highlighted by its presence in the top 5 recommendations by the Society of Hospital Medicine to the Choosing Wisely Campaign. ${ }^{5}$ There have been multiple published studies on efforts to curb telemetry overuse, including educational campaigns, hard-wiring guidelines into the electronic health record (EHR), and discontinuation protocols. ${ }^{6-9}$

Less studied, however, are the causes of telemetry overuse. While lack of knowledge of guidelines may contribute to inappropriate initial ordering of telemetry, ${ }^{1,4}$ physicians may forget to discontinue it when the original indication is no longer present, ie, a form of "clinical inertia." The authors aimed to study how often inpatient clinicians were aware (or unaware) of the telemetry status of their patients.

\section{METHODS}

The authors conducted a cross-sectional observational study at 2 academic medical centers within the same healthcare system (University of California, Los Angeles [UCLA] Health System) over a 10-week period, from December 12, 2014 to February 18, 2015. The survey included senior resident physicians (in years 2 or 3 of training), attending physicians on teaching services ("teaching attendings"), and attending physicians on nonteaching services ("direct-care attendings") caring for hospitalized patients on general internal medicine (nonintensive care) units. First-year residents ("interns") were not surveyed because their presence at interdisciplinary rounds, where surveying took place, was not mandatory. At both hospitals, telemetry is initiated by placing a "Continuous Cardiac Monitoring" order in the EHR, and is terminated by selecting "Discontinue" on that same order. Telemetry status of patients was determined through a daily review of the EHR at UCLA Ronald Reagan Hospital, where presence of telemetry was defined as an active order for telemetry as of 7 AM. At UCLA Santa Monica Hospital, telemetry status was determined by daily review of the morning telemetry technician logs, which reflected telemetry status as of 7 AM.

\footnotetext{
*Address for correspondence and reprint requests: Sajan Patel, University of California, San Francisco, Division of Hospital Medicine, 533 Parnassus Avenue, Box 0131, San Francisco, CA 94143-0131; Telephone: 415-502-5137; Fax: 415-476-4818; Email: sajan.patel@ucsf.edu
}

Received: June 1, 2016; Revised: July 29, 2016; Accepted: August 7, 2016. 2017 Society of Hospital Medicine DOI 10.1002/jhm.2677
Once-weekly, prior to afternoon interdisciplinary rounds, members of the study team would give physicians a print-out of their patient list and ask them to mark whether or not their patients were on telemetry as of that morning. They were allowed to reference their own printed patient list, but were not allowed to reference the EHR. Since interdisciplinary rounds occurred in the afternoon, it was assumed that all clinicians had seen and examined their patients. The authors did not mandate that physicians respond to the survey, and we did not collect information on individual physician characteristics other than training status.

The primary outcome of interest was correct assessment of telemetry status. The authors first presented descriptive statistics for patient, provider, and telemetry status, and used $\chi 2$ tests and McNemar's test to compare the type of physician (resident, teaching attending, or direct-care attending) with the binary outcome (correct or incorrect assessment). STATA/SE, 13.1 (StataCorp), was used for all statistical analysis, and $P$ values $<0.05$ were considered statistically significant. The study was submitted to the UCLA Office of Human Research Protection Program and exempted from Institutional Review Board review.

\section{RESULTS}

A total of 1,379 physician-assessments on 962 patients were obtained during the study period. During this time, $53.1 \%$ (511/962) of patients were on telemetry. Overall, physicians were incorrect in 26.5\% (365/1379) of their assessments of telemetry status (Table). Of the 745 assessments of a patient on telemetry, clinicians erroneously reported that they were not $27.9 \%$ of the time $(n=208)$. Of the 634 assessments of a patient not on telemetry, clinicians erroneously reported that patients were on it $24.8 \%$ of the time $(n=157)$.

Assessments by direct-care attendings were more accurate than those done by teaching attendings $(80.9 \%$ vs. $72.4 \%, P$ $<0.05)$ and resident physicians $(80.9 \%$ vs. $71.8 \%, P<0.05)$. There was no statistically significant difference in accuracy of resident physician assessments when compared to teaching attending assessments $(71.8 \%$ vs. $72.4 \%, P=0.81)$.

\section{DISCUSSION}

In this study, clinicians often inaccurately recalled the telemetry status of their hospitalized patients. These findings have implications for both patient safety as well as telemetry overuse, as ignorance of telemetry status may limit its discontinuation.

The authors also found that assessments done by di- 
TABLE. Assessment of Telemetry Status by Provider

\begin{tabular}{|c|c|c|c|c|}
\hline \multirow[b]{2}{*}{ Provider } & \multicolumn{4}{|l|}{ Assessments/Total (n/N, \%) } \\
\hline & $\begin{array}{l}\text { Erroneously Marked That } \\
\text { Patient Was Not on Telemetry }\end{array}$ & $\begin{array}{l}\text { Erroneously Marked That } \\
\text { Patient Was on Telemetry }\end{array}$ & $\begin{array}{l}\text { Incorrect Assessment of } \\
\text { Telemetry Status }\end{array}$ & $\begin{array}{l}\text { Correct Assessment of Telemetry } \\
\text { Status }\end{array}$ \\
\hline Resident physician ${ }^{\mathrm{a}}$ & $85 / 301(28.2 \%)$ & $70 / 248(28.2 \%)$ & $155 / 549(28.2 \%)$ & $394 / 549(71.8 \%)$ \\
\hline Teaching attending ${ }^{\mathrm{b}}$ & $98 / 332(29.5 \%)$ & $69 / 273(25.2 \%)$ & $167 / 605(27.6 \%)$ & $438 / 605(72.4 \%)$ \\
\hline Direct-care attending (nonteaching service) & $25 / 112(22.3 \%)$ & 18/113 (15.9\%) & 43/225 (19.1\%) & $182 / 225(80.9 \%)$ \\
\hline Total & $208 / 745(27.9 \%)$ & $157 / 634(24.8 \%)$ & $365 / 1,379(26.5 \%)$ & $1014 / 1,379(73.5 \%)$ \\
\hline $\begin{array}{l}\text { a Second- or third-year internal medicine resident wh } \\
\text { b Physician who supervises resident physicians in car } \\
\text { c Physician who cares for hospitalized patients withou }\end{array}$ & $\begin{array}{l}\text { akes care of hospitalized patients under the s } \\
\text { for hospitalized patients } \\
\text { esident physicians }\end{array}$ & ervision of a teaching attending & & \\
\hline
\end{tabular}

rect-care attendings were more accurate than those done by teaching attendings. This discrepancy is likely related to different roles in patient care: teaching attendings provide supervisory roles, while direct-care attendings routinely review orders and perform detailed exams on their patients. Similarly, resident physician assessments were found to be less accurate than direct-care attending assessments, which may reflect less clinical experience as well as their supervisory role.

In light of these findings, interventions to reduce telemetry overuse should include efforts to increase real-time telemetry awareness as well as reduce inappropriate use, and should target all levels of training. Using research on urinary catheter removal ${ }^{10}$ as a model, strategies to increase telemetry awareness could include daily verbal or written reminders of telemetry status, requests to assess daily need, high visibility signs in charts or in patient rooms, or electronic reminders that telemetry is in place. Furthermore, efforts to promote and operationalize medical mindfulness, in which providers are trained to be aware of indications, timely removal, and the presence of monitoring devices could be incorporated into broader telemetry stewardship and high-value care efforts. ${ }^{11}$

There are limitations to this study. The authors did not collect information on the number of unique individual physicians represented by the study, and, thus, clinicians may have been surveyed multiple times throughout the study, potentially influencing their attention to the telemetry status of their patients. In addition, this study was conducted within a single healthcare system, limiting its generalizability.

In conclusion, the authors found that physicians were often incorrect when assessing the telemetry status of their patients. Interventions to help raise awareness of a patient's telemetry status may help reduce telemetry overuse.

Disclosure: Nothing to report.

\section{References}

1. Henriques-Forsythe MN, Ivonye CC, Jamched U, Kamuguisha LKK, Olejeme $\mathrm{KA}$, Onwuanyi AE. Is telemetry overused? Is it as helpful as thought? Cleve Clin J Med. 2009;76:368-372.

2. Kanwar M, Fares R, Minnick S, Rosman HS, Saravolatz L. Inpatient cardiac telemetry monitoring: are we overdoing it. JCOM. 2008;15(1):16-20.

3. Chong-Yik R, Bennett A, Milani R, Morin D. Telemetry overuse and its economic implications. J Am Coll Cardiol.2016;67(13_S):1993.

4. Najafi N, Auerbach A. Use and outcomes of telemetry monitoring on a medicine service. Arch Intern Med. 2012;172:1349-1350.

5. Bulger J, Nickel W, Messler J, et al. Choosing wisely in adult hospital medicine: five opportunities for improved healthcare value. J Hosp Med. 2013;8:486-492.

6. Leighton H, Kianfar H, Serynek S, Kerwin T. Effect of an electronic ordering system on adherence to the American College of Cardiology/American Heart Association guidelines for cardiac monitoring. Crit Pathw Cardiol. 2013;12:6-8.

7. Lee JC, Lamb P, Rand E, Ryan C, Rubal BJ. Optimizing telemetry utilization in an academic medical center. JCOM. 2008;15(9).

8. Boggan JC, Navar-Boggan AM, Patel V, Schulteis RD, Simel DL. Reductions in telemetry order duration do not reduce telemetry utilization. J Hosp Med. 2014;9:795-796.

9. Dressler R, Dryer MM, Coletti C, Mahoney D, Doorey AJ. Altering overuse of cardiac telemetry in non-intensive care unit settings by hardwiring the use of American Heart Association guidelines. JAMA Intern Med. 2014;174:1852-1854.

10. Meddings J, Krein SL, Fakih MG, Olmsted RN, Saint S. Reducing unnecessary urinary catheter use and other strategies to prevent catheter-associated urinary tract infections: brief update review. In: Making Health Care Safer II: An Updated Critical Analysis of the Evidence for Patient Safety Practices. (Evidence Reports/Technology Assessments, No. 211.) Chapter 9. Rockville (MD): Agency for Healthcare Research and Quality (US); 2013. Available from: http://www.ncbi.nlm.nih. gov/books/NBK133354/. May 15, 2016.

11. Kiyoshi-Teo H, Krein SL, Saint S. Applying mindful evidence-based practice at the bedside: using catheter-associated urinary tract infection as a model. Infect Control Hosp Epidemiol. 2013;34:1099-1001. 